\title{
Lobectomy vs. sublobectomy for stage I non-small-cell lung cancer: a meta-analysis
}

\author{
Fang Lv, Bing Wang, Qi Xue, Shugeng Gao \\ Department of Thoracic Surgery, National Cancer Center/National Clinical Research Center for Cancer/Cancer Hospital, Chinese Academy of \\ Medical Sciences and Peking Union Medical College, Beijing, China \\ Contributions: (I) Conception and design: F Lv, S Gao; (II) Administrative support: S Gao; (III) Provision of study materials or patients: F Lv, B Wang, \\ Q Xue; (IV) Collection and assembly of data: F Lv, B Wang, Q Xue; (V) Data analysis and interpretation: F Lv, S Gao; (VI) Manuscript writing: All \\ authors; (VII) Final approval of manuscript: All authors. \\ Correspondence to: Shugeng Gao, PhD. Department of Thoracic Surgery, National Cancer Center/National Clinical Research Center for Cancer/Cancer \\ Hospital, Chinese Academy of Medical Sciences and Peking Union Medical College, Beijing 100021, China. Email: Gaoshugeng@vip.sina.com.
}

Background: Although lobectomy is widely regarded as the treatment of choice for early-stage nonsmall-cell lung cancer (NSCLC), sublobectomy (segmentectomy and wedge resection) has emerged as an alternative modality over the years. Only a handful of studies has compared the treatment effects of these two surgical interventions. This study aimed to analyze the treatment effects between lobectomy and sublobectomy on the survival outcomes of patients with stage I NSCLC systematically.

Methods: PubMed, Embase, and the Cochrane Library were systematically searched from their inception up to February 2019 for studies that compared the survival outcomes of lobectomy and sublobectomy. Studies that reported the diagnosis of stage I NSCLC by imaging or pathophysiology, lobectomy as intervention, sublobectomy as control, and overall survival (OS) and disease-free survival (DFS) as outcomes were included. The mean OS and DFS rates were calculated using the fixed-effects model.

Results: A total of 12 studies that included 4,373 patients with stage I NSCLC were included in the metaanalysis. The patients who underwent lobectomy showed a significant improvement in OS than those who underwent sublobectomy $(\mathrm{P}=0.025)$. These results differed when stratified by publication year (before 2010 and after 2010), study design (prospective and retrospective), country (Eastern and Western), control (segmentectomy and wedge), and study quality (high and low), but no significant differences were observed in DFS. These results were not altered in the sensitivity and subgroup analyses.

Conclusions: Stage I NSCLC patients who undergo sublobectomy display poor OS, whereas the DFS is similar for both methods.

Keywords: Lobectomy; meta-analysis; non-small-cell lung cancer (NSCLC); sublobectomy

Submitted Jan 09, 2020. Accepted for publication Feb 07, 2021.

doi: $10.21037 /$ atm-20-460

View this article at: http://dx.doi.org/10.21037/atm-20-460

\section{Introduction}

Lung cancer is the leading cause of cancer-related mortality worldwide (1). According to the global epidemiological data, over 2 million individuals were affected in 2018 (2). Non-small-cell lung cancer (NSCLC) accounts for approximately $80 \%$ of all diagnosed lung cancers; of these, poor prognosis and non-availability of curative treatment worsen the condition in about $75 \%$ of patients with metastatic or advanced-stage NSCLC (3-5). The long-term prognosis of patients with early-stage NSCLC is reportedly satisfactory, with 5-year survival rates after resection of over 70\% (6-8). High-resolution computed tomography (CT) imaging and low-dose spiral CT imaging help to detect early lung adenocarcinoma $(9,10)$. The Chinese Health Commission's 2018 guidelines for the diagnosis 
and treatment of primary lung cancer classifies the imaging examination as an additional diagnostic modality and suggests histopathological examinations. A biopsy can guide the choice of treatment based on histologic type, molecular profiling, tumor involvement, and, more importantly, the patient's health condition (11).

Although the therapeutic modalities against lung tumors include various methods such as chemotherapy, targeted therapy, immunotherapy, and radiotherapy, surgery remains the treatment of choice since it improves survival rates and reduces treatment-induced adverse effects. Currently, lobectomy remains the standard treatment strategy for patients with early-stage NSCLC (12). Nevertheless, limited resection is often the alternative surgical technique for patients who are not suitable for lobectomy due to advanced age, severely compromised pulmonary function, or other comorbidities (13). Besides, limited resection in earlystage NSCLC is associated with improved lung function preservation and low risk of morbidity and disability, crucial for patients with borderline preoperative cardiopulmonary function $(14,15)$. Currently, segmentectomy and wedge resection are the most common limited resection approaches available. Segmentectomy is an anatomical resection with extensive lymph node dissection, while wedge resection removes the lung tumor and normal lung parenchyma from the margin surrounding the lung (16). Sublobectomy is preferred for tumors $\leq 2 \mathrm{~cm}$ combined with adenocarcinoma in situ, $\geq 50 \%$ ground-glass appearance on CT, or a long doubling radiologic surveillance time ( $\geq 400$ days) (17).

Only a handful of studies have compared the treatment effects of lobectomy and sublobectomy in lung cancer management. Therefore, the present systematic review and meta-analysis aimed to compare the survival outcomes between these two surgical techniques in patients with stage I NSCLC. We present the following article in accordance with the Preferred Reporting Items for Systematic Reviews and Meta-Analysis (PRISMA) reporting checklist (available at http://dx.doi.org/10.21037/atm-20-460).

\section{Methods}

\section{Data sources, search strategy, and selection criteria}

Scholarly databases like PubMed, Embase, and the Cochrane Library were thoroughly searched from their inception up to February 2019 for potential studies, using the following core search terms and strategy: ("lung cancer" OR "NSCLC") AND ("segmentectomy" OR "segmental resection" OR "lobectomy") AND ("sublobar" OR "sublobectomy" OR "wedge") AND "stage I." No language or publication status restrictions were applied. A manual search of the reference lists of the identified relevant articles was also performed.

Two authors independently performed the literature search and study selection. Inconsistencies were settled by group discussions. The inclusion criteria were (I) diagnosis: imaging or pathological confirmation of stage I NSCLC; (II) intervention: lobectomy; (III) control: sublobectomy (segmentectomy and wedge resection); (IV) outcomes: overall survival (OS) and disease-free survival (DFS); and (V) study design: prospective or retrospective.

\section{Data collection and quality assessment}

Two authors independently assessed the abstracts and collected the following key information: first authors' surname, publication year, country, study design, sample size, mean age, percentage male, tumor stage, follow-up period, OS, and DFS. The quality of the included studies was assessed using the Newcastle-Ottawa Scale (NOS) based on selection (representative of the exposed cohort, selection of the non-exposed cohort, ascertainment of exposure, and no outcomes were present at the start of the study), comparability (based on the design or analysis), and outcomes (outcome assessment, and adequate follow-up duration and rate) (18). Two authors assessed the studies' quality, and any disagreement was resolved by a third author referring to the original article. The PRISMA statement was used to report the findings (19).

\section{Statistical analysis}

The treatment effects of lobectomy $v s$. sublobectomy on OS and DFS were studied based on the hazard ratio (HR) and 95\% confidence interval (CI) in each study. Moreover, the pooled HR and $95 \%$ CI for OS and DFS were calculated using the fixed-effects model $(20,21)$. The multivariate HR values were considered from the included studies. Heterogeneity among included studies was tested using the I-square method and $\mathrm{P}$ value for $\mathrm{Q}$ statistic, and $\mathrm{I}$-square $>50.0 \%$ or $\mathrm{P}<0.10$ indicated significant heterogeneity $(22,23)$. Sensitivity analyses for OS and DFS 


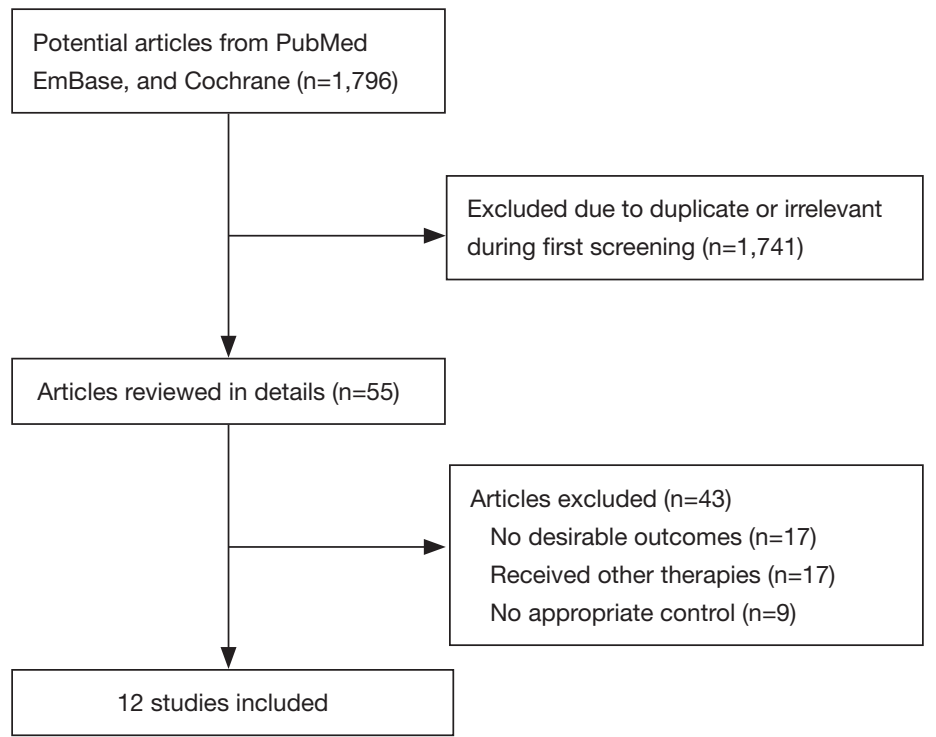

Figure 1 Schematic of the literature search and study selection processes.

were conducted to evaluate the pooled results' stability (24). Subgroup analyses for OS and DFS were conducted based on the publication year, country, mean age, percentage male, control, study quality, and study design. Moreover, $P$ values between subgroups were calculated using interaction tests (25). Publication biases for OS and DFS were evaluated using funnel plots and Egger and Begg tests $(26,27)$. All reported $\mathrm{P}$ values were two-sided, and $\mathrm{P}$ values $<0.05$ were regarded as statistically significant. Statistical analyses were performed using STATA software (version 12.0; Stata Corporation, College Station, TX, USA).

\section{Results}

\section{Literature search}

The electronic searches of databases such as PubMed, Embase, and the Cochrane Library retrieved 1,796 records; 1,741 were duplicates or irrelevant and were excluded. The remaining 55 studies were evaluated, and 43 studies were excluded due to a lack of sufficient data, having chemotherapy or radiotherapy as treatment, or no appropriate control. Finally, 12 studies were selected for the quantitative meta-analysis (28-39). A manual search of the reference lists of the retrieved studies did not yield any further studies. The study selection process's schematic is presented in Figure 1, and the baseline characteristics of the included studies are shown in Table 1.

\section{Study characteristics}

A total of 12 studies published between 2005 and 2017 and 4,373 patients with stage I NSCLC were included in the final analysis. Six studies were conducted in Japan, three in China, two in the USA, and one in Poland. The sample size of the selected studies ranged from 73 to 1,241 . The age of the included patients ranged from 58.9 to 72.0 years, and the proportion of males ranged between $32.9 \%$ and $74.1 \%$. Seven studies included patients with stage Ia NSCLC, and the remaining five studies included patients with stage Ia or Ib NSCLC. The NOS assessment of quality revealed that three studies had eight stars, five studies had seven stars, and the remaining four studies had six stars.

\section{OS}

A total of 11 studies reported an effect of lobectomy $v s$. sublobectomy on OS. The summary results indicated that lobectomy was associated with a significant OS improvement compared with sublobectomy (HR: 0.67; 95\% CI: 0.47-0.95; P=0.025; Figure 2). Significant heterogeneity was detected across the included studies. Sensitivity analyses indicated that the pooled conclusion was altered due to marginal 95\% CI (Tables S1,S2). 
Table 1 Baseline characteristic of studies included in the systematic review and meta-analysis

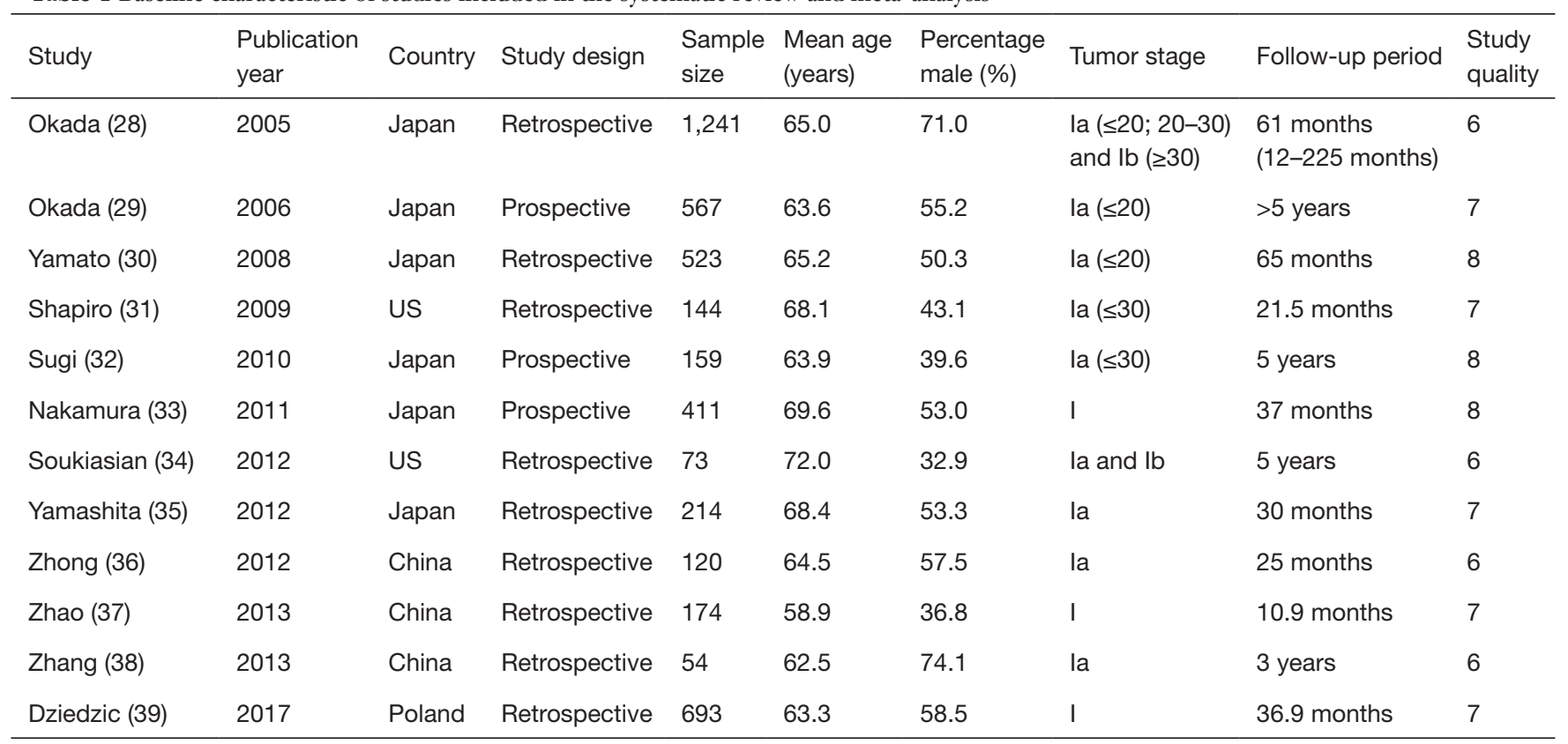

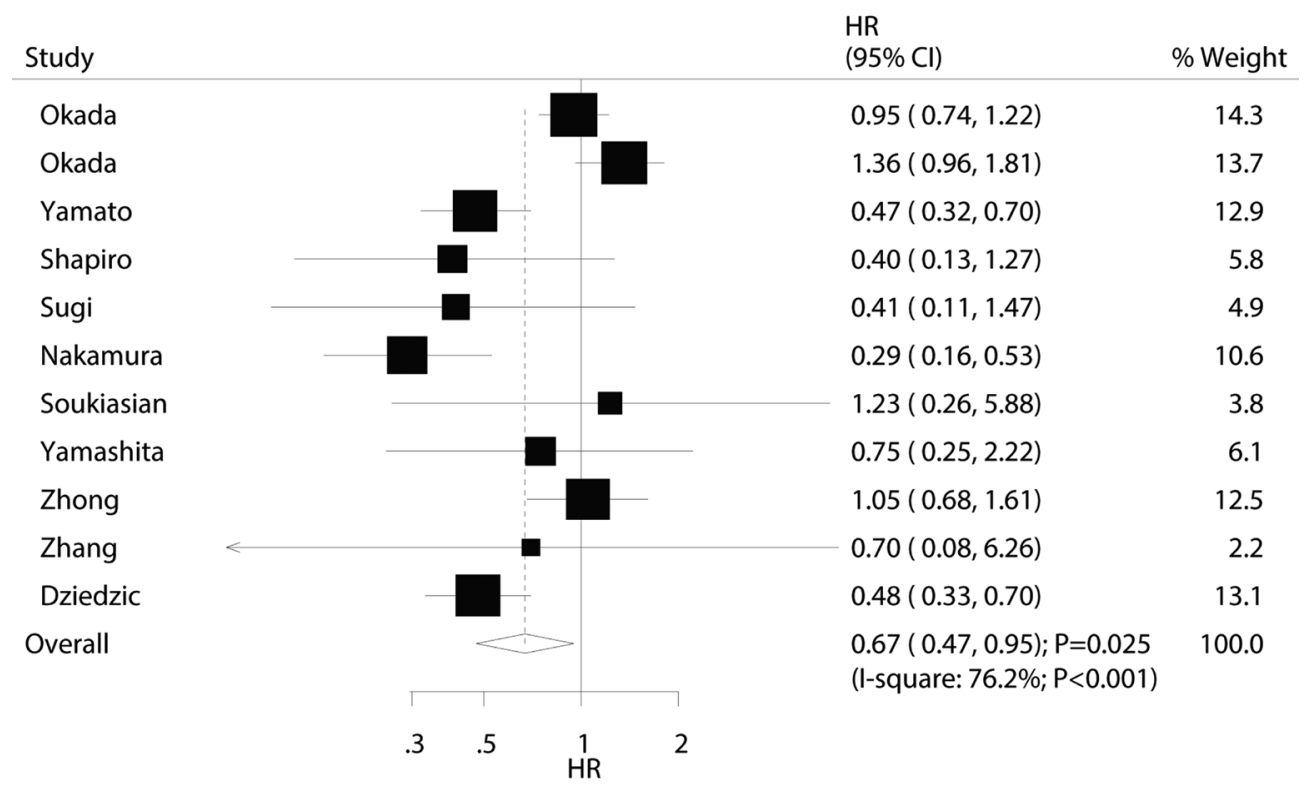

Figure 2 Lobectomy vs. sublobectomy on overall survival (OS) for patients with stage I non-small cell lung cancer (NSCLC).

\section{DFS}

A total of eight studies reported an effect of lobectomy $v$ s. sublobectomy on DFS. Overall, no significant difference was detected between lobectomy and sublobectomy for
DFS (HR: 1.07; 95\% CI: 0.88-1.29; P=0.496; Figure 3). No evidence of heterogeneity was observed. The results were not altered by the sequential exclusion of each study (Tables S1,S2). 


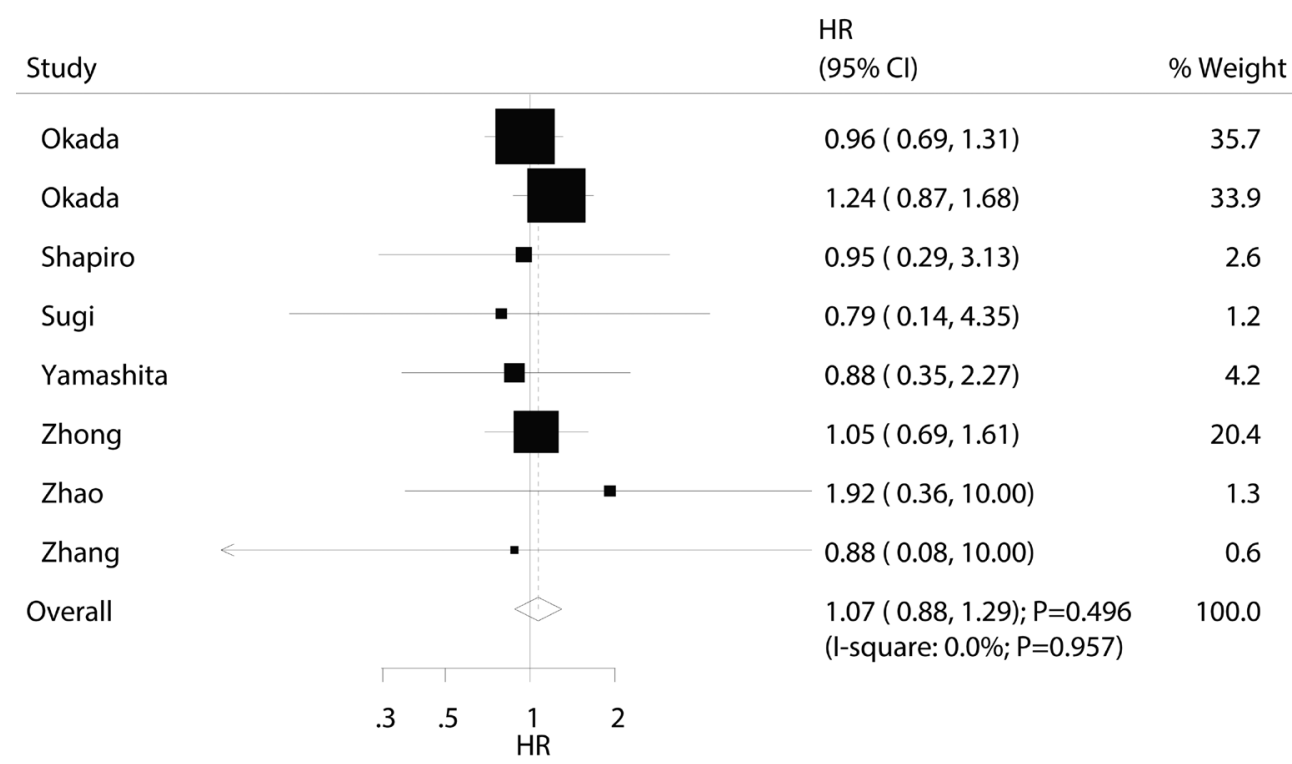

Figure 3 Lobectomy vs. sublobectomy on disease-free survival (DFS) for patients with stage I non-small cell lung cancer (NSCLC).

\section{Subgroup analyses}

Subgroup analyses for OS and DFS based on publication year, country, mean age, percentage of male, control, study quality, and study design were conducted to identify the source of heterogeneity and the treatment effects in patients with specific characteristics. We found that lobectomy, compared with wedge resection, was associated with a significant improvement in OS when the study was published in or after 2010, in Western countries, when the mean age of the patients was $\geq 65.0$ years, when the study was of good quality, and when study design was prospective (Tables S3,S4). Moreover, the subgroup analyses for DFS based on the predefined factors were consistent with the overall analysis in all subsets, and no significant differences were detected between lobectomy and sublobectomy (Tables S3,S4).

\section{Publication bias}

Potential publication bias for OS and DFS could not be excluded by reviewing the funnel plots (Figure $4 A, B$ ), but no potential publication biases were detected for OS $(\mathrm{P}$ value for Egger: 0.327; $\mathrm{P}$ value for Begg: 0.755) and DFS (P value for Egger: 0.789; P value for Begg: 0.902).

\section{Discussion}

This quantitative meta-analysis involving 4,373 patients with stage I NSCLC from 12 studies evaluated the OS and DFS between lobectomy and sublobectomy. Lobectomy was significantly associated with an improvement in OS compared with sublobectomy, but no significant difference was detected in DFS. The treatment effect between lobectomy and sublobectomy on OS was affected by publication year (before 2010 and after 2010), country (Eastern and Western), control (segmentectomy and wedge), study quality (high and low), and study design (prospective and retrospective). In contrast, the predefined factors did not yield any significant impact on the DFS.

A previous meta-analysis of eight studies also demonstrated that lobectomy resulted in a significant improvement in OS compared with sublobectomy, whereas no significant difference was detected for DFS. Moreover, it pointed out that the significant difference in OS was the primary focus compared to wedge resection (40). Nevertheless, the stratification of treatment effects of these surgical techniques by patients' characteristics was unclear. Another meta-analysis of nine studies reported that segmentectomy was associated with a significant improvement in OS and cancer-specific survival compared with wedge resection. In contrast, no significant difference was detected for DFS (41). Even the 2014 meta-analysis of 12 studies indicated that sublobectomy could lower OS in patients with stage 1a NSCLC (42). Of note, several included studies in the present analysis reported conflicting 
A

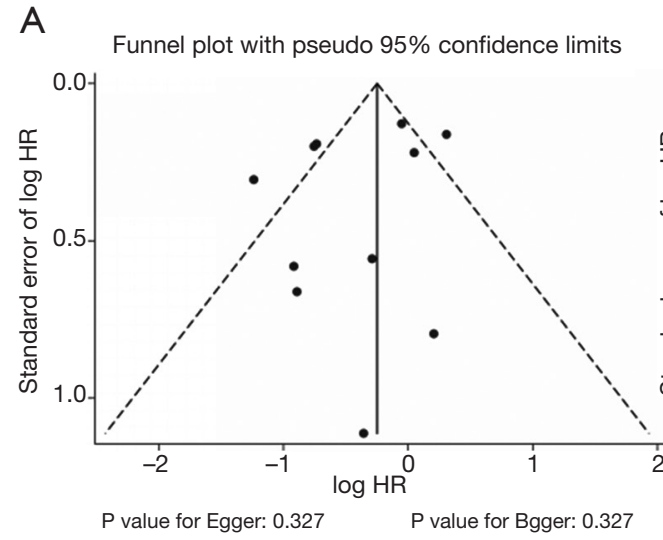

B

Funnel plot with pseudo 95\% confidence limits

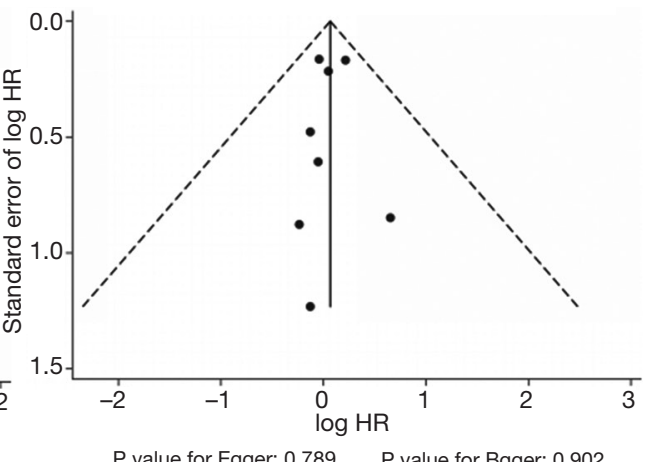

Figure 4 Funnel plot for (A) overall survival (OS) and (B) disease-free survival (DFS).

results. A non-randomized study by Okada et al. involving patients with peripheral cT1N0M0 NSCLC of $\leq 2 \mathrm{~cm}$ indicated that the OS and DFS were similar between lobar and sublobar resections (29). A study also pointed out that the extended segmentectomy was associated with an improved treatment margin (43). Intriguingly, another comparative study in elderly patients also highlighted no significant difference between the OS and DFS rates in stage 1 tumors $<2 \mathrm{~cm}$ (44). A retrospective study of 73 patients with stage I NSCLC suggested that segmentectomy by video-assisted thoracoscopic surgery was comparable to video-assisted thoracoscopic lobectomy, but no significant difference was detected in morbidity or mortality (34). The treatment effect could be attributed to disease staging and comorbidities. Zhong et al. reported that segmentectomy was safe in 120 patients with stage Ia NSCLC, and the survival outcome was comparable to that of lobectomy (36). Moreover, the results could be attributed to the tumor diameters $\leq 20 \mathrm{~mm}$ without nodal involvement. Although several other studies reported no significant difference between lobectomy and sublobectomy on OS, they provided a potentially beneficial trend of lobectomy on OS $(28,31,32,35,38)$.

Furthermore, no significant difference was observed between lobectomy and sublobectomy on DFS, and all the included studies reported similar results. This might vary due to the low incidence of disease relapse and varied follow-up duration among the included studies. Moreover, the width of resection margin, lymph node dissection, or sampling and segment localization could affect local recurrence frequency, and these factors varied among the included studies $(45,46)$.
Different prognostic factors may help to stratify overall prognosis estimates and help choose appropriate surgical intervention in each patient. They provide details on the expected outcomes of a population having unique disease characteristics. Subgroup analyses indicated that publication year, country, control, study quality, and study design could bias the treatment effect on OS by both surgical methods. This phenomenon could be attributed to several interconnected factors. First, the publication year was significantly associated with early diagnosis, disease stage, and background therapies. Second, different countries have different diagnosis and medical levels, which could affect the prognosis. Control strategy could affect the net treatment effect of lobectomy. Lastly, of the 12 studies included, only three received eight stars in the NOS assessment. The study quality and study design were significantly correlated with the reliability and evidence level of individual studies.

The present meta-analysis included several recent studies, and the results have a profound value of evidence on the choice of surgical treatment against lung cancer. Nevertheless, it has several limitations. First, all the included non-randomized studies and uncontrolled confounders could affect the treatment effects between lobectomy and sublobectomy. Second, the treatment effects stratified by patients' characteristics were not considered due to unavailable data. Third, unpublished data were not available, which might be associated with a high falsepositive rate. Finally, the analysis was based on the pooled results; data were not available from the included studies, which restricted the detailed analysis based on the patients' disease status. 


\section{Conclusions}

This meta-analysis indicates a similar DFS between lobectomy and sublobectomy for patients with stage I NSCLC. Lobectomy was associated with a significant improvement in OS compared with sublobectomy. Nonetheless, the results should be substantiated by further prospective randomized controlled trials.

\section{Acknowledgments}

Funding: None.

\section{Footnote}

Reporting Checklist: The authors have completed the PRISMA reporting checklist. Available at http://dx.doi. org/10.21037/atm-20-460

Conflicts of Interest: All authors have completed the ICMJE uniform disclosure form (available at http://dx.doi. org/10.21037/atm-20-460). The authors have no conflicts of interest to declare.

Ethical Statement: The authors are accountable for all aspects of the work in ensuring that questions related to the accuracy or integrity of any part of the work are appropriately investigated and resolved.

Open Access Statement: This is an Open Access article distributed in accordance with the Creative Commons Attribution-NonCommercial-NoDerivs 4.0 International License (CC BY-NC-ND 4.0), which permits the noncommercial replication and distribution of the article with the strict proviso that no changes or edits are made and the original work is properly cited (including links to both the formal publication through the relevant DOI and the license). See: https://creativecommons.org/licenses/by-nc-nd/4.0/.

\section{References}

1. Ferlay J, Shin HR, Bray F, et al. Estimates of worldwide burden of cancer in 2008: GLOBOCAN 2008. Int J Cancer 2010;127:2893-917.

2. World Health Organization [Internet]. Geneva: Cancer; Last updated: 2018 Sep 18; cited 2020 April 24. Available online: https://www.who.int/news-room/fact-sheets/detail/ cancer
3. Reade CA, Ganti AK. EGFR targeted therapy in nonsmall cell lung cancer: potential role of cetuximab. Biologics 2009;3:215-24.

4. Alvarez M, Roman E, Santos ES, et al. New targets for non-small-cell lung cancer therapy. Expert Rev Anticancer Ther 2007;7:1423-37.

5. Ohe Y, Ohashi Y, Kubota K, et al. Randomized phase III study of cisplatin plus irinotecan versus carboplatin plus paclitaxel, cisplatin plus gemcitabine, and cisplatin plus vinorelbine for advanced non-small-cell lung cancer: Four-Arm Cooperative Study in Japan. Ann Oncol 2007;18:317-23.

6. Spiro SG, Porter JC. Lung cancer--where are we today? Current advances in staging and nonsurgical treatment. Am J Respir Crit Care Med 2002;166:1166-96.

7. Nesbitt JC, Putnam JB, Walsh GL, et al. Survival in early-stage non-small cell lung cancer. Ann Thorac Surg 1995;60:466-72.

8. Martini N, Bains MS, Burt ME, et al. Incidence of local recurrence and second primary tumors in resected stage I lung cancer. J Thorac Cardiovasc Surg 1995;109:120-9.

9. Aberle DR, Adams AM, Berg CD, et al. Reduced lungcancer mortality with low-dose computed tomographic screening. N Engl J Med 2011;365:395-409.

10. Callol L, Roig F, Cuevas A, et al. Low-dose CT: a useful and accessible tool for the early diagnosis of lung cancer in selected populations. Lung Cancer 2007;56:217-21.

11. Chinese guidelines for diagnosis and treatment of primary lung cancer 2018 (English version). Chin J Cancer Res 2019;31:1-28.

12. Ettinger DS, Akerley W, Borghaei H, et al. Non-small cell lung cancer, version 2.2013. J Natl Compr Canc Netw 2013;11:645-53; quiz 53.

13. Wisnivesky JP, Henschke CI, Swanson S, et al. Limited resection for the treatment of patients with stage IA lung cancer. Ann Surg 2010;251:550-4.

14. Rami-Porta R, Tsuboi M. Sublobar resection for lung cancer. Eur Respir J 2009;33:426-35.

15. Nomori H, Horio H, Naruke T, et al. What is the advantage of a thoracoscopic lobectomy over a limited thoracotomy procedure for lung cancer surgery? Ann Thorac Surg 2001;72:879-84.

16. Bilfinger TV, Baram D. Sublobar resection in nonsmall cell lung carcinoma. Curr Opin Pulm Med 2008;14:292-6.

17. Yu Y, Huang R, Wang P, et al. Sublobectomy versus lobectomy for long-term survival outcomes of earlystage non-small cell lung cancer with a tumor size $</=2$ $\mathrm{cm}$ accompanied by visceral pleural invasion: a SEER 
population-based study. J Thorac Dis 2020;12:592-604.

18. Wells G, Shea B, O'Connell D. The Newcastle-Ottawa Scale (NOS) for assessing the quality of nonrandomised studies in meta-analyses. Ottawa (ON): Ottawa Hospital Research Institute 2009. Available online: http://www.ohri. ca/programs/clinical_epidemiology/oxford.htm

19. Moher D, Liberati A, Tetzlaff J, et al. Preferred reporting items for systematic reviews and meta-analyses: the PRISMA statement. PLoS Med 2009;6:e1000097.

20. DerSimonian R, Laird N. Meta-analysis in clinical trials. Control Clin Trials 1986;7:177-88.

21. Ades AE, Lu G, Higgins JP. The interpretation of randomeffects meta-analysis in decision models. Med Decis Making 2005;25:646-54.

22. Deeks J, Higgins J, Altman D. Analyzing data and undertaking meta-analyses. In: Higgins J, Green S, eds. Cochrane Handbook for Systematic Reviews of Interventions 501 Oxford, UK: The Cochrane Collaboration 2008; chap 9.

23. Higgins JP, Thompson SG, Deeks JJ, et al. Measuring inconsistency in meta-analyses. BMJ 2003;327:557-60.

24. Tobias A. Assessing the influence of a single study in metaanalysis. Stata Tech Bull 1999;47:15-7.

25. Altman DG, Bland JM. Interaction revisited: the difference between two estimates. BMJ 2003;326:219.

26. Egger M, Davey Smith G, Schneider M, et al. Bias in meta-analysis detected by a simple, graphical test. BMJ 1997;315:629-34.

27. Begg CB, Mazumdar M. Operating characteristics of a rank correlation test for publication bias. Biometrics 1994;50:1088-101.

28. Okada M, Nishio W, Sakamoto T, et al. Effect of tumor size on prognosis in patients with non-small cell lung cancer: the role of segmentectomy as a type of lesser resection. J Thorac Cardiovasc Surg 2005;129:87-93.

29. Okada M, Koike T, Higashiyama M, et al. Radical sublobar resection for small-sized non-small cell lung cancer: a multicenter study. J Thorac Cardiovasc Surg 2006;132:769-75.

30. Yamato Y, Koike T, Yoshiya K, et al. Results of surgical treatment for small (2 cm or under) adenocarcinomas of the lung. Surg Today 2008;38:109-14.

31. Shapiro M, Weiser TS, Wisnivesky JP, et al. Thoracoscopic segmentectomy compares favorably with thoracoscopic lobectomy for patients with small stage I lung cancer. J Thorac Cardiovasc Surg 2009;137:1388-93.

32. Sugi K, Kobayashi S, Sudou M, et al. Long-term prognosis of video-assisted limited surgery for early lung cancer. Eur
J Cardiothorac Surg 2010;37:456-60.

33. Nakamura H, Taniguchi Y, Miwa K, et al. Comparison of the surgical outcomes of thoracoscopic lobectomy, segmentectomy, and wedge resection for clinical stage I non-small cell lung cancer. Thorac Cardiovasc Surg 2011;59:137-41.

34. Soukiasian HJ, Hong E, McKenna RJ Jr. Video-assisted thoracoscopic trisegmentectomy and left upper lobectomy provide equivalent survivals for stage IA and IB lung cancer. J Thorac Cardiovasc Surg 2012;144:S23-6.

35. Yamashita S, Tokuishi K, Anami K, et al. Thoracoscopic segmentectomy for T1 classification of non-small cell lung cancer: a single center experience. Eur J Cardiothorac Surg 2012;42:83-8.

36. Zhong C, Fang W, Mao T, et al. Comparison of thoracoscopic segmentectomy and thoracoscopic lobectomy for small-sized stage IA lung cancer. Ann Thorac Surg 2012;94:362-7.

37. Zhao X, Qian L, Luo Q, et al. Segmentectomy as a safe and equally effective surgical option under complete videoassisted thoracic surgery for patients of stage I non-small cell lung cancer. J Cardiothorac Surg 2013;8:116.

38. Zhang L, Ma W, Li Y, et al. Comparative study of the anatomic segmentectomy versus lobectomy for clinical stage IA peripheral lung cancer by video assistant thoracoscopic surgery. J Cancer Res Ther 2013;9 Suppl 2:S106-9.

39. Dziedzic R, Zurek W, Marjanski T, et al. Stage I nonsmall-cell lung cancer: long-term results of lobectomy versus sublobar resection from the Polish National Lung Cancer Registry. Eur J Cardiothorac Surg 2017;52:363-9.

40. Liu Q, Wang H, Zhou D, et al. Comparison of clinical outcomes after thoracoscopic sublobectomy versus lobectomy for Stage I nonsmall cell lung cancer: A metaanalysis. J Cancer Res Ther 2016;12:926-31.

41. Hou B, Deng XF, Zhou D, et al. Segmentectomy versus wedge resection for the treatment of high-risk operable patients with stage I non-small cell lung cancer: a metaanalysis. Ther Adv Respir Dis 2016;10:435-43.

42. Liu Y, Huang C, Liu H, et al. Sublobectomy versus lobectomy for stage IA (T1a) non-small-cell lung cancer: a meta-analysis study. World J Surg Oncol 2014;12:138.

43. Yoshikawa K, Tsubota N, Kodama K, et al. Prospective study of extended segmentectomy for small lung tumors: the final report. Ann Thorac Surg 2002;73:1055-8; discussion 1058-9.

44. Qiu C, Wang G, Xu J, et al. Sublobectomy versus lobectomy for stage I non-small cell lung cancer in the 
elderly. Int J Surg 2017;37:1-7.

45. Sienel W, Stremmel C, Kirschbaum A, et al. Frequency of local recurrence following segmentectomy of stage IA nonsmall cell lung cancer is influenced by segment localisation and width of resection margins--implications for patient

Cite this article as: Lv F, Wang B, Xue Q, Gao S. Lobectomy $v s$. sublobectomy for stage I non-small-cell lung cancer: a metaanalysis. Ann Transl Med 2021;9(9):751. doi: 10.21037/atm-20460 selection for segmentectomy. Eur J Cardiothorac Surg 2007;31:522-7; discussion 527-8.

46. Swanson SJ. Video-assisted thoracic surgery segmentectomy: the future of surgery for lung cancer? Ann Thorac Surg 2010;89:S2096-7. 


\section{Supplementary}

Table S1 Sensitivity analysis for OS

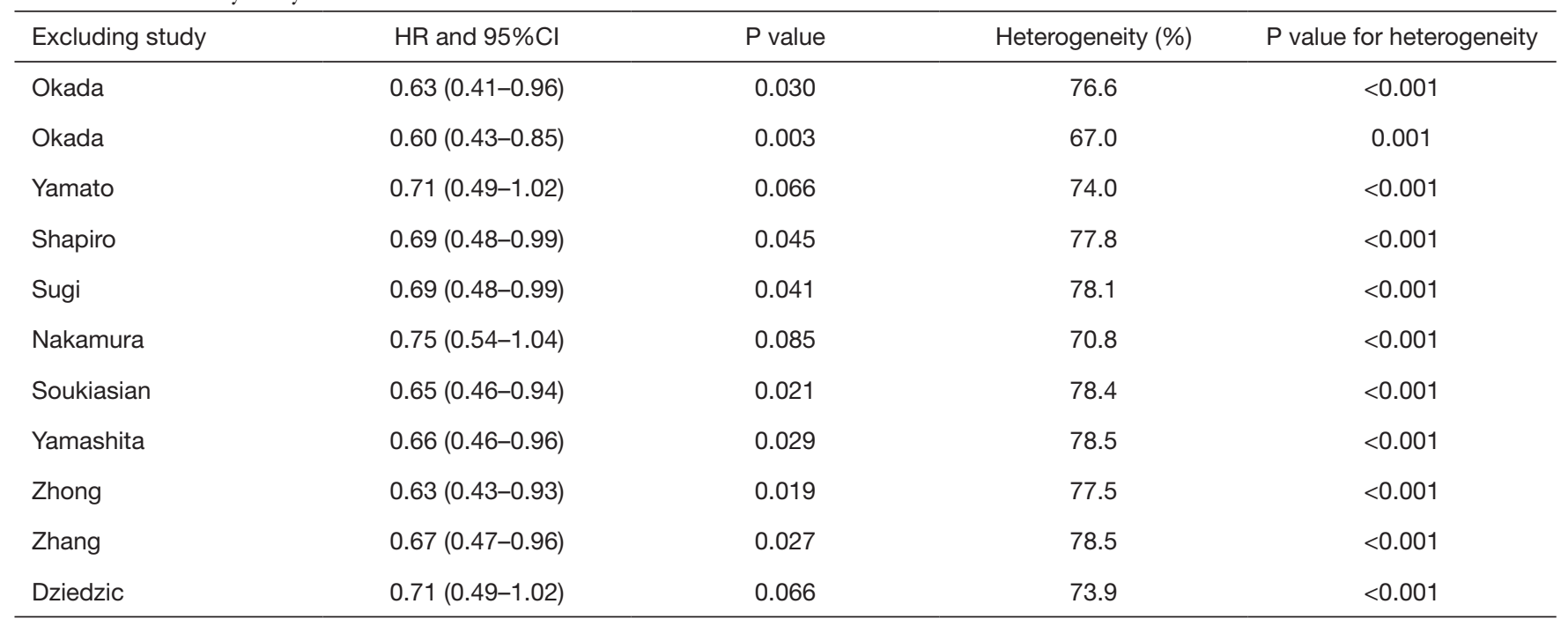

Table S2 Sensitivity analysis for DFS

\begin{tabular}{lcccc}
\hline Excluding study & $\mathrm{HR}$ and $95 \% \mathrm{Cl}$ & $\mathrm{P}$ value & Heterogeneity (\%) & P value for heterogeneity \\
\hline Okada & $1.13(0.89-1.44)$ & 0.301 & 0.0 & 0.967 \\
Okada & $0.99(0.78-1.25)$ & 0.936 & 0.0 & 0.990 \\
Shapiro & $1.07(0.88-1.30)$ & 0.482 & 0.0 & 0.919 \\
Sugi & $1.07(0.88-1.30)$ & 0.475 & 0.0 & 0.926 \\
Yamashita & $1.08(0.89-1.31)$ & 0.452 & 0.0 & 0.931 \\
Zhong & $1.07(0.87-1.33)$ & 0.517 & 0.0 & 0.916 \\
Zhao & $1.06(0.87-1.29)$ & 0.551 & 0.0 & 0.955 \\
Zhang & $1.07(0.88-1.30)$ & 0.490 & 0.0 & 0.918 \\
\hline
\end{tabular}


Table S3 Subgroup analysis for OS

\begin{tabular}{|c|c|c|c|c|c|c|}
\hline Factors & Group & $\mathrm{HR}$ and $95 \% \mathrm{Cl}$ & $P$ value & Heterogeneity (\%) & $\begin{array}{c}\mathrm{P} \text { value for } \\
\text { heterogeneity }\end{array}$ & $\begin{array}{l}P \text { value between } \\
\text { groups }\end{array}$ \\
\hline Publication year & Before 2010 & $0.78(0.47-1.29)$ & 0.336 & 84.4 & $<0.001$ & 0.005 \\
\hline \multirow[t]{2}{*}{ Country } & Eastern & $0.72(0.48-1.07)$ & 0.101 & 78.5 & $<0.001$ & 0.005 \\
\hline & Western & $0.49(0.35-0.70)$ & $<0.001$ & 0.0 & 0.480 & \\
\hline Mean age (years) & $<65.0$ & $0.80(0.46-1.39)$ & 0.428 & 79.2 & 0.001 & \\
\hline \multirow[t]{2}{*}{ Percentage male (\%) } & $\geq 50.0$ & $0.70(0.47-1.02)$ & 0.065 & 82.2 & $<0.001$ & 0.288 \\
\hline & $<50.0$ & $0.52(0.25-1.11)$ & 0.091 & 0.0 & 0.472 & \\
\hline Study quality & Low & $0.98(0.79-1.21)$ & 0.819 & 0.0 & 0.954 & \\
\hline \multirow[t]{2}{*}{ Study design } & Prospective study & $0.68(0.56-0.83)$ & 0 & 0 & 0.648 & $<0.001$ \\
\hline & Retrospective study & $0.67(0.59-0.76)$ & $<0.001$ & 0 & 1.000 & \\
\hline
\end{tabular}

Table S4 Subgroup analysis for DFS

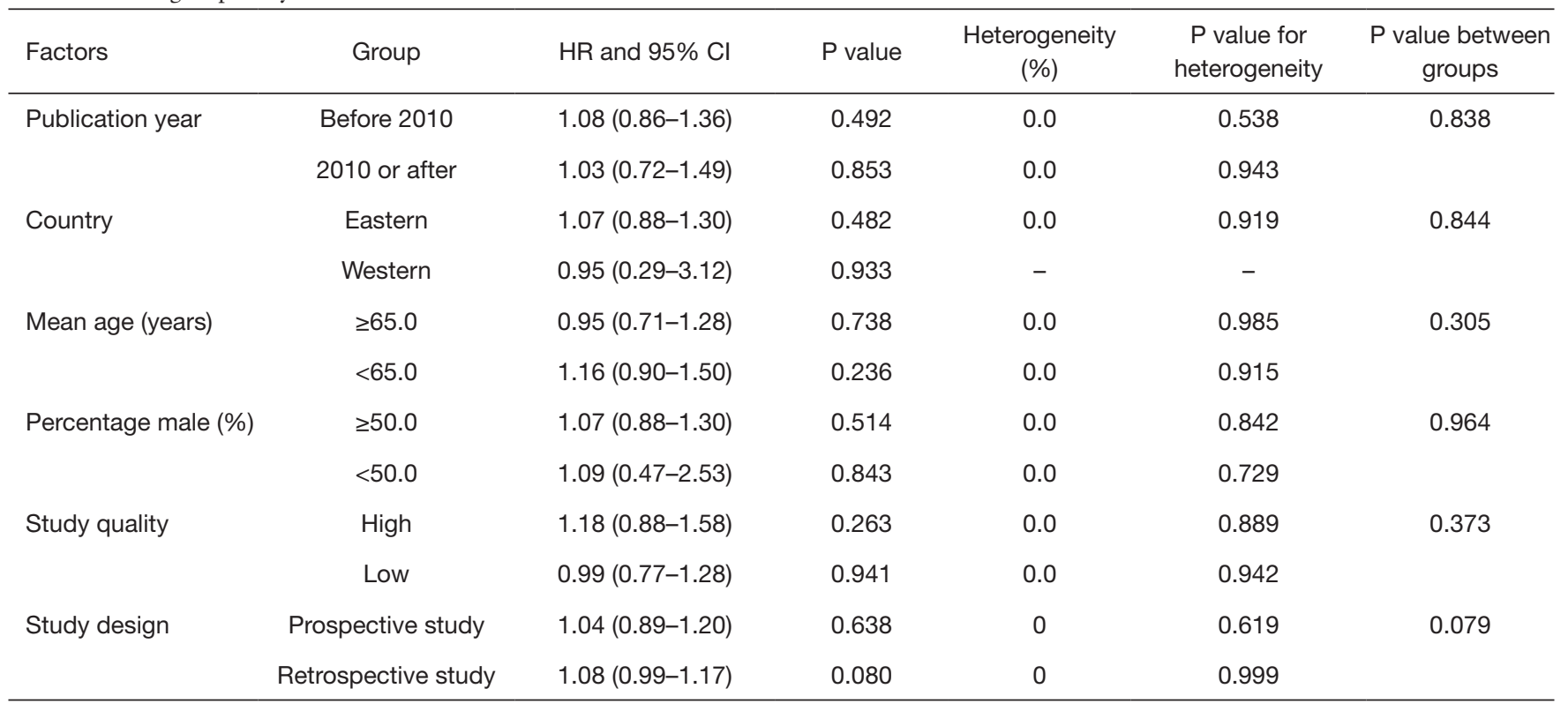

